Revista Brasileira de

Engenharia Agrícola e Ambiental

v.13, n.4, p.487-493, 2009

Campina Grande, PB, UAEA/UFCG - http://www.agriambi.com.br

Protocolo 194.07 - 06/12/2007 • Aprovado em 25/11/2008

agriambi

\title{
Tratamento biológico do bagaço de maçã e adição em dietas para alevinos
}

\author{
Francielo Vendruscolo ${ }^{1}$, Cristiéle S. Ribeiro ${ }^{2}$; Elisa Espósito ${ }^{2}$ \& Jorge L. Ninow ${ }^{1}$
}

\section{RESUMO}

0 tratamento biológico do bagaço de maçã pelo fungo Gongronella butleri, através do processo de fermentação em estado sólido e adição deste material na al imentação de tilápias do nilo, é parte fundamental do estudo ora apresentado, razão pela qual se avaliaram a fonte de nitrogênio, a umidade inicial e a granulometria no tratamento biológico do bagaço de maçã, obtendo-se as melhores condições com uréia como fonte de nitrogênio, umidade inicial de $70 \%$ e granulometria na faixa de 0,85 a 1,68 mm, produzindo 19,63\% de proteína solúvel. O s peixes submetidos a dieta contendo $30 \%$ ( $\mathrm{p} \mathrm{p} \mathrm{p}^{-1}$ ) do material tratado biologicamente na ração convencional, apresentaram aumento de $44 \%$ na massa corporal com diferenças significativas a nível de 0,05 quando comparados com os al evinos alimentados apenas com ração convencional.

Palavras-chave: resíduos agroindustriais, fermentação em estado sólido, O reochromis niloticus, Gongronella butleri

\section{Biological treatment of apple pomace and addition in diet for fish}

\begin{abstract}
The biological treatment of the apple pomace by Gongronella butleri in solid state fermentation and the addition of this material in fish feeding (Nile tilapia) was the fundamental part of this study. The source of nitrogen, initial moisture and granulometry in the biological treatment were appraised. The best conditions being obtained with urea, initial moisture of $70 \%$ and granulometry from 0.85 to $1.68 \mathrm{~mm}$, producing $19.63 \%$ of soluble protein. The fish submitted to the diet containing treated apple pomace $(30 \% \mathrm{wb}$ ) presented an increase of $44 \%$ in the corporal mass presenting significant differences at the level of 0.05 .
\end{abstract}

Key words: agro-industrial residues, state solid fermentation, O reochromis niloticus, Gongronella butleri

${ }^{1}$ EQA/UFSC, C P 476, CEP 88040-900, Florianópolis, SC. Fone (48) 3721-9448. Email: francielo@enq.ufsc. br; jorge@enq.ufsc.br

${ }^{2}$ Núcleo de Ciências Ambientais Universidade de Mogi das Cruzes. CEP 08780-911, Mogi das Cruzes, SP. Email: elisa@umc.br; cristiele_bio@yahoo.com.br 


\section{INTRODUÇÃO}

Proteínas de Organismo Unicelular (POU) são células secas de microrganismos cultivadas em grande escala e utilizadas como fonte de proteína para alimentação humana e animal (Anupama \& Ravindra; 2000). Desde os tempos antigos as algas foram utilizadas como fonte alimentar por povos que habitavam as margens dos Lagos Chad, na África, e Texcoco, no México, os quais utilizavam a microalga Spirulina platensis como alimento (Singh et al., 1998). As bactérias mais utilizadas como fontes de proteínas unicelulares, são a Cellulomonas e Alcaligenes, revelando o seu potencial de bactérias fototróficas para a produção de POU (Anupama \& Ravindra; 2000; Rajoka et al., 2006). Fungos filamentosos e leveduras também são reportados como fontes de proteínas e podem ser utilizados como POU. Aspergillus niger (Singh et al., 1998), Saccharomyces cerevisiae (Kolani et al., 1996; Singh et al., 1998), Fusarium graminearum (Singh et al., 1998), Penicillium cyclopium (Kim \& Lebeault, 1981) e fungos brancos de podridão (Zadrazil \& Puniya, 1995) são exemplos de microrganismos utilizados mundialmente, como fontes de POU; referidos microrganismos podem ser cultivados em diferentes substratos que, geralmente, são oriundos da indústria processadora de alimentos; possuem, como características principais, açúcares redutores, materiais fibrosos e diversos nutrientes essenciais para o desenvolvimento desses microrganismos (Anupama \& Ravindra; 2000).

No Brasil, por se tratar do maior estado produtor nacional de maçãs, produzindo aproximadamente 800 mil toneladas por ano (ABPM, 2007) Santa Catarina gera grandes quantidades de resíduos sólidos, em que o principal é o bagaço de maçã. Este resíduo é produzido a partir da obtenção do suco de maçã por indústrias de sucos, geléias, doces e aromas (Albuquerque et al., 2006; Sudha et al., 2007; Villas-Bôas, 2001).

Os frutos que não atendem aos requisitos para comercialização in natura, são destinados ao uso industrial, limpos e higienizados; em seguida, é feita a extração do suco, por prensagem. O material sólido, composto de cascas, sementes e polpa, gerado nesta etapa, é denominado bagaço de maçã. Este material possui elevada quantidade de carboidratos e fibras, constituídas de biopolímeros de alta massa molar, possui baixo conteúdo de proteínas, aminoácidos essenciais, vitaminas e sais (Albuquerque et al., 2006; Pirmohammadi et al., 2006; Sudha et al., 2007; Vendruscolo et al., 2008; Zheng \& Shetty, 1998). Atualmente, este material é vendido aos agricultores da região pelo valor simbólico de U\$ 1,50 $\mathrm{t}^{-1}$ para ser utilizado como adubo orgânico ou ração animal.

Em virtude de seu elevado conteúdo de açúcares, o bagaço de maçã se torna um substrato em potencial, para utilização em processos biotecnológicos, atuando como fonte de carbono para microrganismos; sua conversão em produtos mais nobres vem aumentando nos últimos anos (Vendruscolo et al., 2008). Em várias pesquisas se tem utilizado o bagaço de maçã como fonte de carbono para microrganismos, dentre elas: produção de ácido cítrico (Shojaosadati \& Babaeipour, 2002), ácido láctico (Gullón et al., 2008), SCP (Joshi \& Sandhu, 1996; Rajoka et al., 2006; Vendruscolo et al., 2007; Villas-
Bôas, 2001), fungos comestíveis (Zheng \& Shetty, 1998), enzimas (Zheng \& Shetty, 2000) e etanol (Ngadi \& Correia, 1992).

Com a rápida expansão da produção de peixes nos anos recentes, surge a demanda por fontes alternativas de proteínas em dietas para reduzir o custo com alimentação, que representa de 50 a $80 \%$ do custo de produção (Cavalheiro et al., 2007; El-Sayed, 1999). Os resíduos agroindustriais se apresentam como matérias-primas ricas, do ponto de vista da produção de proteína unicelular porém muitas vezes não são aproveitadas mas descartadas diretamente no ambiente, onde causam sério impacto. $\mathrm{O}$ aproveitamento biotecnológico desses resíduos, além de diminuir o teor de poluentes, é responsável pela produção de um alimento com excelente perfil nutricional aumentando, com isto, seu valor agregado (Sabra, 2004). Várias fontes de proteínas e carboidratos, como polpa de café (Ulloa Rojas \& Verreth, 2003), caroço de algodão (Dabrowsky et al., 2002), Moringa oleifera (Dongmeza et al., 2006; Richter et al., 2003), levedura Torulla sp. (Novoa et al., 2002), resíduos de camarão (Cavalheiro et al., 2007) e amido (Abdolsamad et al., 2006) têm sido utilizados na alimentação de tilápias.

A adição do bagaço de maçã enriquecido pelo cultivo de um fungo filamentoso em dieta para peixes pode ser uma forma de valoração deste resíduo agroindustrial, reduzindo não só problemas ambientais, mas e ao mesmo tempo, custos com alimentação, ante o que se objetivou no presente trabalho, a valoração do bagaço de maçã através do enriquecimento protéico pelo processo de fermentação em estado sólido e sua adição como complemento alimentar em dietas de tilápia do Nilo (Oreochromis niloticus).

\section{MATERIAL E MÉTODOS}

\section{Microrganismo e meio de cultivo}

O microrganismo utilizado foi o fungo filamentoso Gongronella butleri CCT 4274, obtido da Coleção de Culturas Tropicais da Fundação André Tosello (Campinas, SP), mantido em ágar dextrose de batata (PDA) a $4{ }^{\circ} \mathrm{C}$.

$\mathrm{O}$ bagaço de maçã utilizado nos experimentos e fornecido pela empresa Yakult S.A. localizada no município de Lages, SC, mantido a $-20^{\circ} \mathrm{C}$, foi descongelado e secado em estufa a $50{ }^{\circ} \mathrm{C}$, durante $24 \mathrm{~h}$, triturado e peneirado em peneiras da série Tyler (6-8 mesh), sendo coletada a fração correspondente a $-1,68+3,35 \mathrm{~mm}$ (partículas maiores que 1,68 e menores que $3,35 \mathrm{~mm}$ ). Realizou-se o ajuste de umidade do bagaço de maçã pela adição de água destilada, contendo a fonte de nitrogênio em solução e autoclavado a $121^{\circ} \mathrm{C}$, durante $15 \mathrm{~min}$. Após resfriamento, o bagaço de maçã, foi transferido, em condições assépticas, para as colunas de Raimbault, previamente esterilizadas, e inoculado com $4 \times 10^{6}$ esporos por grama de meio seco, incubado a $30{ }^{\circ} \mathrm{C}$, sob aeração de $0,4 \mathrm{~L} \mathrm{~min}^{-1}$ coluna $^{-1}$ durante 7 dias.

\section{Delineamento experimental}

No enriquecimento protéico do bagaço de maçã avaliouse a fonte de nitrogênio, a umidade inicial e a granulometria, 
além de se realizar a estimativa dos efeitos empregandose o Software Statistica 6.0. Para avaliar a fonte de nitrogênio (sulfato de amônio, nitrato de sódio e uréia) e a umidade inicial do meio de cultivo (50, 60 e 70\%), realizou-se um planejamento experimental fatorial $3^{2}$ (2 variáveis em 3 níveis); determinou-se, a partir dos resultados obtidos no primeiro planejamento, a melhor fonte de nitrogênio para o enriquecimento protéico do bagaço de maçã; subseqüentemente, foi realizado o segundo planejamento experimental fatorial $2^{2}$ ( 2 variáveis em 2 níveis) para avaliar a umidade inicial $(60$ e $70 \%)$ e a granulometria $(-0,86+1,68 \mathrm{~mm}$, fração retida entre as peneiras de 10 a 20 mesh e $-1,68+3,35 \mathrm{~mm}$, fração retida entre as peneiras de 6 a 10 mesh). As matrizes, com as variáveis codificadas e as variáveis reais utilizadas nos experimentos, encontram-se apresentadas na Tabela 1.

Tabela 1. Matriz com as variáveis codificadas e as variáveis reais utilizadas nos experimentos

\begin{tabular}{ccc}
\hline \multicolumn{3}{c}{ Planejamento experimental factorial 3a } \\
\hline Níveis & Fonte de nitrogênio & Umidade Inicial (\%) \\
-1 & Sulfato de amônio & 50 \\
0 & Nitrato de sódio & 60 \\
+1 & Uréia & 70 \\
-1 & 60 & $0,86-1,70$ \\
+1 & 70 & $1,70-3,35$ \\
\hline
\end{tabular}

Determinaram-se, a partir do planejamento experimental fatorial $2^{2}$, as condições do tratamento biológico do bagaço de maçã utilizado na alimentação dos alevinos (uréia como fonte de nitrogênio, umidade inicial de $70 \%$ e a granulometria na faixa de $-0,86+1,68 \mathrm{~mm}$ ).

\section{Determinação de proteína solúvel e açúcares redutores}

Determinou-se a concentração de proteína solúvel conforme metodologia proposta por Lowry et al. (1951) e o conteúdo de açúcares redutores pelo método do ácido 3,5dinitrosalicílico (3,5-DNS), descrito por Miller (1959). Para extração da proteína solúvel e os açúcares, $5 \mathrm{~g}$ do material foram adicionados em balões volumétricos de $100 \mathrm{~mL}$ que tiveram seu volume ajustado com água destilada. Após incubação em banho-maria a $60^{\circ} \mathrm{C}$ durante $3 \mathrm{~h}$, o material foi filtrado em papel filtro qualitativo e o extrato submetido às análises de proteína solúvel e açúcares redutores. A quantidade de nitrogênio total no bagaço de maçã foi determinada pela metodologia de Kjeldahl e o teor de cinzas no bagaço de maçã, pela metodologia proposta pela AOAC (1995).

\section{Determinação dos parâmetros biométricos}

Os testes biológicos foram realizados em alevinos de tilápia (Oreochromis niloticus) fornecidos pela empresa MOGIVET, localizada no município de Mogi das Cruzes, SP. As dietas, convencional (RC), com $28 \%$ de proteína, e experimental (RCB - Ração com Bagaço de maçã tratado Biologicamente) adicionadas em $30 \%\left(\mathrm{p} \mathrm{p}^{-1}\right)$ foram avaliadas em quatro aquários contendo 30 alevinos cada um. A cada 15 dias se realiza- ram as medidas de comprimento, altura e massa dos alevinos e os resultados foram comparados mediante análise de variância.

\section{RESULTADOS E DISCUSSÃO}

\section{Tratamento biológico}

A partir do planejamento experimental fatorial realizado com duas variáveis em três níveis (dados não mostrados), verificou-se que os experimentos realizados com nitrato de sódio e uréia, ambos com conteúdo de umidade de $70 \%$, indicaram maiores quantidades de proteína solúvel, 14,80 $\pm 0,32$ e 15,22 $\pm 0,51 \%$ respectivamente e, quando realizados na umidade de $60 \%$, os resultados foram próximos a 14,13 $\pm 0,64$ e 13,65 \pm $0,11 \%$, demonstrando que tanto a uréia quanto o nitrato de sódio aumentaram consideravelmente a quantidade de proteína solúvel no material tratado, o que pode ser verificado através da Figura 1.
A.

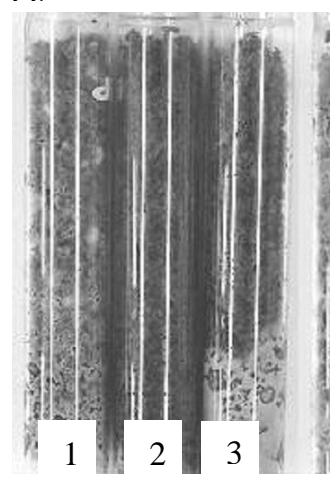

B.

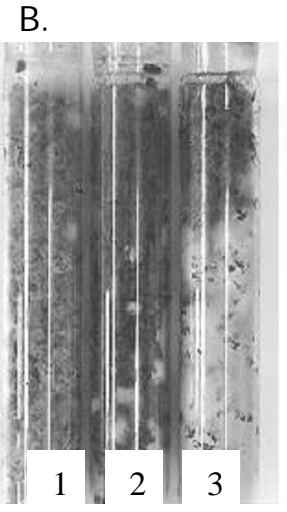

C.

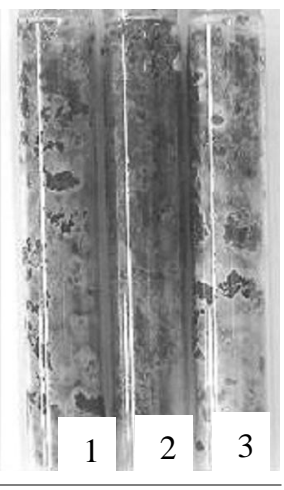

Figura 1. Cultivos de G. butleri em colunas de Raimbault com diferentes fontes de nitrogênio. U réia (1), sulfato de amônio (2) e nitrato de sódio (3), após 7 dias de cultivo: umidade inicial 50\% (A); umidade inicial 60\% (B) e umidade inicial $70 \%(C)$

Analisando-se a Figura 1, vê-se que os experimentos realizados com sulfato de amônio mostraram baixo crescimento celular, enquanto para os experimentos realizados com nitrato de sódio e uréia, o meio de cultivo foi totalmente colonizado pelo fungo ao final de sete dias. O crescimento do fungo em meio suplementado com uréia, induziu a esporulação, enquanto o nitrato de sódio propiciou o crescimento micelial; a umidade também mostrou ser um parâmetro preponderante a ser considerado, haja vista que diferentes níveis de umidade para a mesma fonte de nitrogênio apresentaram diferenças significativas, sendo $70 \%$ a umidade inicial que mais favoreceu o crescimento do fungo (Figura 1C).

Bisaria et al. (1997) utilizaram o fungo Pleurotus sajor-caju na bioconversão de palha de arroz e palha de trigo e constataram que a suplementação do resíduo sólido com uréia e nitrato de amônio aumentou a taxa de bioconversão. O teor protéico foi aumentado de 2,9 para 6,3\% na palha de arroz e de 3,1 para 7,5\% na palha de trigo. Zheng \& Shetty (1998) empre- 
garam bagaço de maçã e o fungo Rhizopus oligosporus para a produção de um alimento rico em proteínas. Altos teores de umidade resultaram no aumento da produção micelial, interferindo na transferência de oxigênio e baixos teores de umidade reduziram o crescimento fúngico.

A partir desses resultados, a uréia foi usada como fonte de nitrogênio devido ao seu menor custo relativo e se procedeu, então, à avaliação da umidade (60 e 70\%) e granulometria $(-0,85+1,68$ e $-1,68+3,35 \mathrm{~mm})$ por meio de um planejamento experimental fatorial (duas variáveis em dois níveis). A Tabela 2 mostra a matriz do planejamento experimental fatorial com as variáveis reais e as respostas proteína solúvel e redução no conteúdo de açúcares redutores no bagaço de maçã.

Tabela 2. Matriz com as variáveis reais e respostas para 0 planejamento experimental fatorial

\begin{tabular}{|c|c|c|c|c|}
\hline \multirow[b]{2}{*}{ Ensaio } & \multicolumn{2}{|c|}{ Variáveis Reais } & \multicolumn{2}{|c|}{ Respostas } \\
\hline & (1)Um (\%) & ${ }^{(2)} \mathrm{Gr}(\mathrm{mm})$ & (3)PS (\%) & ${ }^{(4)}$ ARC (\%) \\
\hline 1 & 60 & $-0,85+1,68$ & $15,96 \pm 0,35$ & $53,53 \pm 1,25$ \\
\hline 2 & 60 & $-1,68+3,35$ & $15,87 \pm 0,78$ & $54,81 \pm 0,21$ \\
\hline 3 & 70 & $-0,85+1,68$ & $19,63 \pm 0,55$ & $66,79 \pm 0,63$ \\
\hline 4 & 70 & $-1,68+3,35$ & $17,48 \pm 0,18$ & $58,86 \pm 2,18$ \\
\hline${ }^{(5)} \mathrm{C}$ & - & - & $8,72+0,41$ & $7,10 \pm 0,23$ \\
\hline${ }^{(6)} \mathrm{B}$ & - & - & $5,94 \pm 0,20$ & $0,50 \pm 0,10$ \\
\hline
\end{tabular}

${ }^{(1)} \mathrm{Um}$ - umidade; ${ }^{(2)} \mathrm{Gr}$ - granulometria; ${ }^{(3)} \mathrm{PS}$ - proteína solúvel; ${ }^{(4)} \mathrm{ARC}$ - açúcares redutores consumidos; ${ }^{(5)} \mathrm{B}$ - bagaço de maçã sem tratamento biológico e ${ }^{(6)} \mathrm{C}$ - bagaço de maçã tratado sem adição de nutrientes

Verifica-se, analisando-se a Tabela 2 , que o experimento 3 , realizado com umidade de $70 \%$ e granulometria de 0,85 a 1,68 $\mathrm{mm}$, resultou em maior produção de proteína solúvel atingindo valores médios de $19,63 \%$, aumentando o conteúdo protéico do bagaço de maçã em 3,2 vezes quando comparado com o bagaço de maçã sem tratamento (B).

Determinaram-se os efeitos e valores de $\mathrm{p}$ da variável umidade inicial e granulometria, demonstrando que ambas apresentaram efeito significativo $(\mathrm{p}<0,05)$ sobre a produção de proteína solúvel. Pela análise dos efeitos isolados, fornecidos pelo Software Statistica 6.0, verifica-se que a umidade inicial de $70 \%$ aumenta em média $2,64 \%$ o conteúdo de proteína solúvel no bagaço de maçã enquanto a variável granulometria aumenta em média 1,12\% quando utilizada a granulometria na faixa de 0,85 a $1,68 \mathrm{~mm}$.

A maioria dos experimentos apresentou reduções significativas no conteúdo de açúcares redutores; esta redução, além de ser um indicativo do crescimento celular é também um aspecto importante em virtude da redução da carga orgânica, uma vez que este material é submetido à alimentação de peixes e o conteúdo de açúcares está diretamente relacionado à carga orgânica adicionada.

APHA/AWWA/WEF (1992) citam que a presença de um alto teor de matéria orgânica pode induzir a completa extinção do oxigênio na água, provocando o desaparecimento de peixes e outras formas de vida aquática e aumentando custos com o sistema de oxigenação de lagoas. Um valor elevado da DBO pode indicar um incremento da microbiota pre- sente e interferir no equilíbrio da vida aquática, além de produzir sabores e odores desagradáveis.

Zadrazil \& Puniya (1995) utilizaram fungos de decomposição branca para avaliar o efeito do tamanho de partícula utilizando, como substrato para fermentação em estado sólido, o bagaço de cana-de-açúcar. Menores granulometrias favorecem a conversão do substrato em biomassa devido ao aumento da área superficial, porém Bianchi et al. (2001) relatam que o tamanho de partícula do substrato pode ser problemático, uma vez que o substrato necessita de uma granulometria que permita a circulação de ar através do leito fermentativo e a dissipação de gases e calor produzidos durante o crescimento microbiano.

Joshi \& Sandhu (1996) utilizaram três leveduras (Saccharomyces, Candida e Torula) para a produção de álcool a partir do bagaço de maçã, utilizando fermentação em estado sólido. Após separação do álcool, o bagaço de maçã fermentado foi avaliado quanto ao conteúdo de proteína solúvel, açúcares redutores, lipídeos e valor calórico, em que os resultados demonstraram que o conteúdo de proteína solúvel aumentou uma vez e meia, reduzindo em $42 \%$ o conteúdo de açúcares redutores.

Villas-Bôas \& Esposito (2000) cultivaram Candida utilis e Pleurotus ostreatus no bagaço de maçã. Quando o bagaço foi tratado com $C$. utilis durante seis dias, foi possível aumentar em $100 \%$ o teor de proteína bruta observando-se, ainda, uma redução de até $97 \%$ no conteúdo de açúcares livres no substrato.

Albuquerque et al. (2006) utilizaram o fungo filamentoso Rhizopus oligosporus no enriquecimento protéico do bagaço de maçã em que os resultados demonstraram que o conteúdo de proteína solúvel aumentou cinco vezes na melhor condição de cultivo. O microrganismo indicou grande potencial na bioconversão do bagaço de maçã, chegando a produzir 30\% de proteína na melhor condição de cultivo verificada.

\section{Testes biológicos e parâmetros biométricos}

Com o objetivo de testar o bagaço de maçã tratado biologicamente com G. butleri como complemento alimentar em ração animal, duas dietas foram administradas para os alevinos de tilápia-do-Nilo, durante 30 dias, além de ração convencional (RC), controle e a ração convencional suplementada em 30\% ( $\left.\mathrm{p} \mathrm{p}^{-1}\right)$ com bagaço de maçã tratado (RCB). Os índices " 0 " (zero) e " 30 " (trinta) se referem às medidas iniciais e finais para as respostas comprimento, altura e massa dos alevinos.

Tem-se, na Tabela 3, os valores médios iniciais e finais dos alevinos submetidos às diferentes dietas para cada parâmetro biométrico avaliado.

Os alevinos alimentados com dieta contendo $30 \%\left(\mathrm{p} \mathrm{p}^{-1}\right)$ de bagaço de maçã tratado biologicamente apresentaram aumento em todos os parâmetros biométricos medidos ao final de 30 dias, quando comparados com os alevinos alimentados com dieta contendo apenas ração convencional (Tabela 3), indicando que a adição deste material pode aumentar a produtividade, reduzindo os custos de produção.

A Tabela 4 apresenta a análise de variância para as respostas comprimento, altura e massa corpórea dos alevinos 
Tabela 3. Medidas iniciais e finais para os parâmetros biométricos avaliados em cada dieta

\begin{tabular}{cccc}
\hline $\begin{array}{c}\text { Parâmetros } \\
\text { Biométricos }\end{array}$ & Dieta & Inicial & Final \\
Altura $(\mathrm{cm})$ & $\mathrm{RC}$ & $0,97 \pm 0,16$ & $1,30 \pm 0,35$ \\
& $\mathrm{RCB}$ & $0,97 \pm 0,18$ & $1,45 \pm 0,43$ \\
Comprimento $(\mathrm{cm})$ & $\mathrm{RC}$ & $3,39 \pm 0,40$ & $4,59 \pm 0,60$ \\
& $\mathrm{RCB}$ & $3,37 \pm 0,42$ & $5,10 \pm 0,79$ \\
Massa Corpórea $(\mathrm{g})$ & $\mathrm{RC}$ & $0,60 \pm 0,28$ & $1,60 \pm 0,62$ \\
& $\mathrm{RCB}$ & $0,58 \pm 0,21$ & $2,30 \pm 1,09$ \\
\hline
\end{tabular}

para os dois experimentos. Não houve diferença significativa $(p>0,05)$ no crescimento dos alevinos alimentados com RC (0) e RCB (0), demonstrando a viabilidade da substituição parcial da ração convencional pela proteína microbiana.

Analisando-se os dados da Tabela 4, verifica-se que as comparações iniciais entre os alevinos do experimento RC (0) e RCB (0) para as três respostas avaliadas não indicaram diferenças estatisticamente significativas a nível de 0,05 mas, sim, a homogeneidade dos alevinos utilizados nos experimentos. Analisando-se a resposta altura dos alevinos ao final de 30 dias, constata-se que os alevinos submetidos a dieta RC apresentaram altura média de $1,30 \mathrm{~cm}$ enquanto os alevinos submetidos a dieta RCB mostraram altura média de $1,45 \mathrm{~cm}$, representando um aumento de 11,5\%; esses resultados, por sua vez, indicam que a adição de bagaço de maçã fermentado à ração convencional aumentou em média $0,15 \mathrm{~cm}$ a altura dos alevinos não apresentando, porém, diferenças significativas $(p>0,05)$ entre as dietas realizadas.

De acordo com a resposta comprimento dos alevinos ao final de 30 dias de alimentação, nota-se que os alevinos submetidos a dieta RC apresentaram comprimento de 4,59 cm

Tabela 4. Diferença entre médias e análise de variância para as respostas comprimento, altura e massa corpórea dos alevinos alimentados com ração convencional e experimental

\begin{tabular}{|c|c|c|c|}
\hline Comparação & Diferença $(\mathbf{c m})$ & $q$ & Valor de $p$ \\
\hline \multicolumn{4}{|c|}{ Altura } \\
\hline$R C(0)-R C(30)$ & $-0,33$ & 6,30 & $<0,001$ \\
\hline$R C(0)-R C B(0)$ & 0,00 & 0,06 & $>0,050$ \\
\hline$R C(0)-R C B(30)$ & $-0,48$ & 8,87 & $<0,001$ \\
\hline $\mathrm{RC}(30)-\mathrm{RCB}(0)$ & 0,33 & 6,36 & $<0,001$ \\
\hline$R C(30)-R C B(30)$ & $-0,14$ & 2,64 & $>0,050$ \\
\hline $\mathrm{RCB}(0)-\mathrm{RCB}(30)$ & $-0,47$ & 8,93 & $<0,001$ \\
\hline \multicolumn{4}{|c|}{ Comprimento } \\
\hline$R C(0)-R C(30)$ & $-1,19$ & 9,29 & $<0,001$ \\
\hline$R C(0)-R C B(0)$ & 0,02 & 0,39 & $>0,050$ \\
\hline$R C(0)-R C B(30)$ & $-1,70$ & 13,84 & $<0,001$ \\
\hline $\mathrm{RC}(30)-\mathrm{RCB}(0)$ & 1,21 & 10,31 & $<0,001$ \\
\hline $\mathrm{RC}(30)-\mathrm{RCB}(30)$ & $-0,50$ & 4,03 & $<0,050$ \\
\hline$R C B(0)-R C B(30)$ & $-1,72$ & 14,21 & $<0,001$ \\
\hline \multicolumn{4}{|c|}{ Massa Corpórea } \\
\hline$R C(0)-R C(30)$ & $-1,00$ & 8,31 & $<0,001$ \\
\hline$R C(0)-R C B(0)$ & 0,01 & 0,14 & $>0,050$ \\
\hline$R C(0)-R C B(30)$ & $-1,70$ & 14,09 & $<0,001$ \\
\hline $\mathrm{RC}(30)-\mathrm{RCB}(0)$ & 1,01 & 8,45 & $<0,001$ \\
\hline $\mathrm{RC}(30)-\mathrm{RCB}(30)$ & $-0,70$ & 5,84 & $<0,001$ \\
\hline $\mathrm{RCB}(0)-\mathrm{RCB}(30)$ & $-1,71$ & 14,23 & $<0,001$ \\
\hline
\end{tabular}

enquanto os alevinos submetidos a dieta RCB atingiram 5,10 $\mathrm{cm}$, aumentando em $13 \%$ o comprimento dos alevinos, indício de diferenças significativas ( $\mathrm{p}<0,05)$, proporcionando um aumento médio de $0,50 \mathrm{~cm}$, sinal de que a adição do bagaço de maçã tratado biologicamente na ração convencional, apresenta resultados positivos na alimentação de alevinos.

Para a resposta massa corpórea, os alevinos submetidos a dieta RCB atingiram, em média, 2,30 g, enquanto os alevinos submetidos a dieta RC apresentaram, em média, 1,60 g; esta diferença de 0,70 g por alevino representa um aumento de aproximadamente $44 \%$ na massa corpórea. Analisando-se os resultados da Tabela 4, verifica-se que a comparação RC (30) - RCB (30) mostrou diferenças significativas ( $p<0,001$ ), assumindo que a adição do bagaço de maçã tratado biologicamente aumenta a massa dos alevinos ao final de 30 dias de alimentação, fato este indicado indiretamente pelo aumento do comprimento e da altura dos alevinos, demonstrando que o bagaço de maçã tratado biologicamente com o fungo filamentoso Gongronella butleri pode ser utilizado parcialmente como substituto alimentar em dietas para alevinos de tilápia.

Baccarin \& Pezzato (2001) avaliaram o efeito da adição de $10 \%$ da levedura Saccharomyces cerevisiae desidratada, como substituto do suplemento vitamínico em dietas para tilápia-do-Nilo. Os resultados não transpareceram influência significativa sobre o ganho de peso e taxa de crescimento específico. Os peixes que receberam levedura apresentaram menor conteúdo corporal de proteína e maior de lipídeos.

Davies \& Wareham (1988) afirmaram, em experimentos realizados com tilápia mossâmbica, que a inclusão de até $10 \%$ de proteína unicelular não reduz o desempenho produtivo. Níveis superiores resultaram em redução substancial na taxa de crescimento.

Cavalheiro et al. (2007) utilizaram silagem de resíduo de camarão com $40 \%$ de proteína em dietas para tilápia do Nilo em substituição à farinha de peixe. A adição da silagem, no entanto, não apresentou diferenças significativas ( $\mathrm{p}>0,05)$ em relação à dieta padrão, realizada com ração comercial, nas respostas massa e comprimento, durante o período de 60 dias, demonstrando que a silagem de camarão pode substituir a farinha de peixe em rações comerciais, diminuindo custos de produção.

Albrektsen et al. (2006) avaliaram, em salmão, a adição de soja e milho na proporção de 2:1 em dietas contendo 46, 67 e $91 \%$ de proteína, cujos indivíduos apresentaram um aumento de 167 para 690 g na massa corpórea, não apresentando, porém, diferenças significativas $(\mathrm{p}>0,05)$ para as três dietas realizadas mas demonstrando que a mistura de soja e milho pode ser utilizada na substituição em até $50 \%$ na dieta desses peixes.

Dabrowski et al. (2002) avaliaram a adição de caroço de algodão na proporção de $0,25,50,75$ e 100\% em dietas visando à substituição do conteúdo protéico em dietas para tilápias. Os resultados confirmaram que com adição de até $50 \%$ de caroço de algodão nas dietas, os peixes apresentaram crescimento similar à dieta controle $(\mathrm{p}>0,05)$. As dietas que indicaram composições superiores apresentaram redução 
no crescimento com diferenças significativas comparadas ao controle $(\mathrm{p}<0,05)$.

Lara-Flores et al. (2002) utilizaram a levedura alcoólica úmida, em dietas de tilápias (Oreochromis niloticus) durante 10 semanas, para posterior observação do nível ótimo de substituição, sendo que o tratamento com $30 \%$ de substituição demonstrou o melhor índice de digestibilidade (80\%), e a comparação com a dieta sem leveduras mostrou que esta ração apresenta índices de digestibilidade e crescimento significativamente inferiores, quando comparados com as dietas com levedura, demonstrando que as dietas atuam como promotoras de crescimento e inativadoras de fatores estressantes, como o manejo e densidade de estocagem da espécie testada.

Os resultados desta substituição se mostram bastante promissores e respondem às expectativas do $2^{\circ}$ Simpósio Internacional de Aqüicultura Sustentável, realizado em Oslo, Noruega, em 1998, em que substituições de fontes protéicas animais por fontes alternativas de proteínas nas rações foram fortemente recomendadas.

\section{CONCLUSÕES}

1. As colunas de Raimbault preenchidas com bagaço de maçã suplementado com uréia foram totalmente colonizadas por Gongronella butleri ao final de sete dias de cultivo, demonstrando que este material pode ser convertido biologicamente pelo fungo.

2. Obteve-se a maior concentração de proteína solúvel nos experimentos realizados com umidade inicial de $70 \%$, uréia na concentração de 5\% como fonte de nitrogênio e granulometria na faixa de 0,85 a 1,68 mm, produzindo $19,63 \%$ de proteína microbiana.

3. A adição de $30 \%$ do bagaço de maçã tratado biologicamente à ração convencional para alimentação de peixes, proporcionou aumento significativo a nível de 0,05 , nos parâmetros biométricos comprimento e massa corpórea dos alevinos de tilápia, além de apresentar grande aceitabilidade.

4. Mesmo nas fases iniciais do desenvolvimento dos alevinos, quando a atividade metabólica é pronunciada devido ao crescimento acelerado, a proteína microbiana demonstrou suprir a demanda energética dos alevinos.

\section{AGRADECIMENTOS}

Ao CNPq, pela bolsa de Mestrado concedida a Francielo Vendruscolo; à CAPES, pela bolsa de Mestrado concedida a Cristiéle da Silva Ribeiro; à FAPESP, processo no 05/55837-6, e à empresa Yakult S.A, localizada no município de Lages, SC.

\section{LITERATURA CITADA}

Abdolsamad, K. A.; Verreth, J. A. J.; Schrama, J. W. Effect of gelatinization degree and inclusion level of dietary starch on the characteristics of digestion and faeces in Nile tilapia (Oreochromis niloticus). Aquaculture, v.260, n.1, p.194-205, 2006.
ABPM - Associação Brasileira dos Produtores de Maçãs. http:// www.abpm.org.br. 20 Jan. 2007.

Albrektsen, S.; Mundheim, H.; Aksnes, A. Growth, feed efficiency, digestibility and nutrient distribution in Atlantic cod $(\mathrm{Ga}$ dus morhua) fed two different fish meal qualities at three dietary levels of vegetable protein sources. Aquaculture, v.261, n.2, p.626-640, 2006.

Albuquerque, P. M.; Koch, F.; Trossini, T. G.; Esposito, E.; Ninow, J. L. Production of Rhizophus oligosporus protein by solid state fermentation of apple pomace. Brazilian Archives of Biology and Technology, v.49, n.5, p.91-100, 2006.

Anupama, R. P. Value-added food: Single cell protein. Biotechnology Advances, v.18, n.6, p.459-479, 2000.

AOAC - Association of Official Analytical Chemists, 16.ed., Official methods of analysis, Washington: AOAC 1995. $529 \mathrm{p}$.

APHA/AWWA/WEF. Standard methods for the examination of water and wastewater, 18 ed., Washington: American Public Health Association, 1992. 1193p.

Baccarin, A. E.; Pezzato, L. E. Efeito da utilização da levedura desidratada de álcool em dietas para tilápia-do-nilo. Pesquisa Agropecuária Brasileira, v.36, n.3, p.549-556, 2001.

Bianchi, V. L. del; Moraes, I. O.; Capalbo, D. M. F. Fermentação em estado sólido. In: Schmidell, W.; Lima, U. A.; Aquarone, E.; Borzani, W. (ed.). Biotecnologia industrial. São Paulo: Edgard Blücher, 2001, cap.13, p.247-270.

Bisaria, R.; Madan, M.; Vasudevan, P. Utilization of agro-residues as animal feed through bioconversion. Bioresource Technology, v.59, n.1, p.5-8, 1997.

Cavalheiro, J. M. O.; Souza, E. O.; Bora, P. S. Utilization of shrimp industry waste in the formulation of tilapia (Oreochromis niloticus Linnaeus) feed. Bioresource Technology, v.98, n.3, p.602-606, 2007.

Dabrowski, M.; El-Saidy; Wisner, N. Growth, feed utilization and body composition of tilapia (Oreochromis sp.) fed with cottonseed meal based diets in a recirculating systems. Aquaculture Nutrition, v.7, n.3, p.189-195, 2002.

Davies, S.; Wareham, H. A preliminary evaluation of an industrial single cell protein in practical diets for tilapia (Oreochromis mossambicus). Aquaculture, v.73, n.2, p.189-199, 1988.

Dongmeza, E.; Siddhuraju, P.; Francis, G.; Becker, K. Effects of dehydrated methanol extracts of Moringa oleifera Lam. leaves and three of its fractions on growth performance and feed nutrient assimilation in Nile tilapia (Oreochromis niloticus L.). Aquaculture, v.261, n.1, p.407-422, 2006.

El-Sayed, A. F. M. Alternative dietary protein sources for farmed tilapia, Oreochromis niloticus sp. Aquaculture, v.179, n.3, p.149-168, 1999.

Gullón, B.; Yánez, R.; Alonso, J. L.; Paraió, J. C. L-lactic acid production from apple pomace by sequential hydrolysis and fermentation. Bioresource Technology, v.99, n.2, p.309-319, 2008.

Joshi, V. K.; Sandhu, D. K. Preparation and evaluation of an animal feed by product produced by solid-state fermentation of apple pomace. Bioresource Technology, v.56, n.2-3, p.251-255, 1996. 
Kim, J. H.; Lebeault, J. M. Protein production from whey using Penicillium cyclopium: growth parameters and cellular composition. European Journal Applied Microbiology and Biotechnology, v.13, n.3, p.151-154, 1981

Kolani, S.; Delgenes, J. P.; Moletta, R.; Traore, Q.; Doh, A. Optimization of cell yield of Candida krusei SO1 and Saccharomyces $\mathrm{sp}$. LK3G culture in sorghum hydrolysate. Bioresource Technology, v.57, n.3, p.275-281, 1996.

Lara-Flores, M.; Briones, L.; Olvera Novoa, M. Avances en la utilización de probióticos como promotores de crecimiento en tilapia nilótica (Oreochromis niloticus). In: Cruz-Suárez, L. E.; Ricque-Marie, D.; Tapia-Salazar, M.; Gaxiola-Cortés, M. G.; Simoes, N. (ed.). Avances en nutrición acuícola. Memorias del Simposium Internacional de Nutrición Acuícola, 6, 2002, Cancún. Anais... Cancún: CICESE, 2002. p.314-335.

Lowry, O. H.; Rosebrough, N. J.; Farr, A. L. Protein measurement with the folin phenol reagent. Journal of Biology and Chemistry, v.193, n.1, p.265-271, 1951.

Miller, G. L. Use of dinitrosalicilic acid reagent for determination of reducing sugar. Analytical Chemistry, v.31, n.9, p.426-428. 1959.

Ngadi, M. O.; Correia, L. R. Kinetics of solid state ethanol fermentation from apple pomace. Journal of Food Engineering, v.17, n.2, p.97-116, 1992.

Novoa, M. A. O.; Palacios, C. A. M.; Castilho, L. O. Utilization of Torula yeast (Candida utilis) as a protein source in diets for tilapia (Oreochromis mossambicus Peters) fry. Aquaculture Nutrition, v.8, n.4, p.257-263, 2002.

Pirmohammadi, R.; Rouzbehan, Y.; Rezayazdi, K.; Zahedifar, M. Chemical composition, digestibility and in situ degradability of dried and ensiled apple pomace and maize silage. Small Ruminant Research, v.66, n.1, p.150-155, 2006.

Rajoka, M. I.; Khan, S. H.; Jabbar, M. A.; Awan, M. S.; Hashmi, A. $\mathrm{S}$. Kinetics of batch single cell protein production from rice polishings with Candida utilis in continuously aerated tank reactors. Bioresource Technology, v.97, n.15, p.1934-1991, 2006.

Richter, N.; Siddhuraju, P.; Becker, K. Evaluation of nutritional quality of moringa (Moringa oleifera Lam.) leaves as an alternative protein source for Nile tilapia (Oreochromis niloticus L.) Aquaculture, v.217, n.1-4, p.599-611, 2003.

Sabra, G. E. Aproveitamento biotecnológico do soro de queijo para produção de proteína microbiana por Kluyveromyces marxianus. Mogi das Cruzes: UMC, 2004. 87p. Dissertação Mestrado
Shojaosadati, S.A.; Babaeipour, V. Citric acid production from apple pomace in multi-layer packed bed solid-state bioreactor. Process Biochemistry, v.37, n.8, p.909-914, 2002.

Singh, A.; Abidi, A. B.; Agarwal, A. K.; Dharmwal, N. S. Single cell protein production from Aspergillus niger and its evaluation. Zentralbl Microbiology, v.3, n.3, p.149-181, 1998.

Sudha, M. L.; Baskaran, V.; Leelavathi, K. Apple pomace as a source of dietary fiber and polyphenols and its effect on the rheological characteristics and cake making. Food Chemistry, v.104, n.2, p.686-692, 2007.

Ulloa Rojas, J. B.; Verreth, J. A. J. Growth of Oreochromis aureus fed with diets containing graded levels of coffee pulp and reared in two culture systems. Aquaculture. v.217, n.1, p.275283, 2003.

Vendruscolo, F.; Albuquerque, P.; Streit, F.; Esposito, E.; Ninow, J. L. Apple pomace: A versatile substrate for biotechnological applications. Critical Reviews in Biotechnology. v.28, n.1, p.1-12, 2008.

Vendruscolo, F.; Koch, F.; Pitol, L. O.; Ninow, W. J. L. Produção de proteína unicelular a partir do bagaço de maçã utilizando fermentação em estado sólido. Revista Brasileira de Tecnologia Agroindustrial, v.1, n.1, p.53-57, 2007.

Villas-Bôas, S. G. Conversão do bagaço de maçã por Cândida utilis e Pleurotus ostreatus visando a produção de suplemento animal. Florianópolis: UFSC, 2001. 126p. Dissertação Mestrado

Villas-Bôas, S. G.; Esposito, E. Bioconversão do bagaço de maçã: Enriquecimento nutricional utilizando fungos para produção de um alimento alternativo de alto valor agregado. Biotecnologia Ciência e Desenvolvimento, v.14, n.1, p.38-42, 2000.

Zadrazil, F.; Puniya, A. K. Studies on effect of particle size on solid state fermentation of sugarcane bagasse into animal feed using white rot fungi. Bioresource Technology, v.54, n.1, p.8587, 1995.

Zheng, Z.; Shetty, K. Solid-state production of beneficial fungi on apple processing wastes using glucosamine as the indicator of growth. Journal of Agricultural and Food Chemistry, v.46, n.2, p.783-787, 1998.

Zheng, Z.; Shetty, K. Enhancement of pea (Pisum sativum) seedling vigour and associated phenolic content by extracts of apple pomace fermented with Trichoderma spp. Process Biochemistry, v.36, n.1, p.79-84, 2000. 